\title{
Service life modelling of timber structures
}

\author{
J.-W. G. van de Kuilen
}

Received: 16 June 2005/ Accepted: 15 November 2005/Published online: 18 October 2006

(C) RILEM 2006

\begin{abstract}
The service life of structures depends on many factors including the current status of the structures and the age, as well as the expected future use. In order to be able to make decisions on possible interventions, an overview is given of a number of methods available to determine the current state of a structure. Data taken from existing structures (foundations) with and without biological decay as well as literature have been analysed. It has been used to extent an existing damage model for timber structures that takes the load history into account into a model that allows for service life calculations on partly deteriorated structures. This comprises structures or structural elements that suffer for instance from (biological) decay or from drying cracks as is often found in foundations and historic timber structures.
\end{abstract}

Keywords Timber piles - Durability · Service life modelling $\cdot$ Damage

\footnotetext{
J.-W. G. van de Kuilen 2600 GA, Delft, The Netherlands

J.-W. G. van de Kuilen $(\varangle)$

CNR-Ivalsa, Florence, Italy

e-mail: j.w.g.vandekuilen@tudelft.nl
}

Faculty of Civil Engineering and Geosciences, Delft University of Technology, P.O. Box 5048,

\section{Introduction}

Timber as a structural material may be found in many buildings and structures around Europe, with a current age of sometimes more than 500 years. Already in the Roman era the foundations were made with timber both in form of horizontal beams under brick walls and as vertical piles for deeper foundations. But the increase in building activities from the Renaissance period until about 50 years ago has seen a great use of timber. The use of timber is widely spread: timber can be found in foundations of famous heritage buildings such as the Royal Palace in Amsterdam, the Netherlands and bridges in Venice (Siviero and Murat 1993). Timber foundations are in these cases true foundations of cultural heritage and therefore their economic and technical importance is large. A complication in the assessment is that pile foundations are difficult to inspect and maintain, and yet many thousands of buildings and structures depend on them. The historic centres of many Dutch cities were all built during the Middle Ages and the golden age from about 1400 until recently. Besides the Netherlands and Italy, piles have been used in countries like France, Germany and also in North America. Failure of the foundation, either because of loss of strength or because of excessive deformations, may have severe consequences for the structure it is supporting. Timber with age of up to 500 years 
can also be found in many floor and roof structures. The Palazzo Vecchio in Florence, Italy is a fine example. Irrespectively of the applications, the assessment of these structures for their safety and serviceability requires models that take into account the history of the structure. Not only the timber species, also the loads on the structure over history and expected future loads are important in the assessment procedure. Although most of the timber foundations known worldwide are in very good condition, assessments of the quality and the load carrying capacity often have to be made. The objective of the research is to determine the residual load carrying capacity of old foundation elements and to develop a model allowing predictions for the remaining lifetime. It will be shown that damage accumulation models, which take into account age, load history and current state of the material properties, can be used in such an assessment procedure of timber structures. Focus is given to the assessment of pile foundations, since a reasonable amount of test data is present. However, the method of service life calculations can easily be extended to other structures as will be shown. An example with regard to the future lifetime of a timber pile foundation is given.

\section{Assessment of timber structures}

\subsection{Reasons for assessment}

There are several reasons why an assessment of timber structures may be necessary or can be justified at a certain moment in time. In the following a list is given which covers most of the calls for assessment in the Netherlands, but the list is probably valid for most areas in the world where timber is used in structural applications, from foundations to upper structures.

Damage of the (upper) structure: When structures show signs of deterioration by means of cracks, this might be due to diminishing performance of the load bearing timber foundation structure. Causes of performance loss can be long term loads or excessive creep deformations.

Re-use of timber: Structures are sometimes demolished after their service life. The timber could be re-used for new planned structures, and consequently the structural performance has to be assessed.

Change of use in the upper structure: Residential houses from centuries ago are often changed into office spaces. The (design) loads on the structural elements as well as on the foundation will increase accordingly. A typical ratio between residential floor loads and office floor loads is 1.8-2.5 [Eurocode 1].

Alterations and changes in the upper structure: Floors may be added and attics are being put into use, timber floors are reinforced with a concrete layer, walls are removed, replaced or added to name just a few of possible alterations that may require an assessment of the structure and foundation.

Underground building activities: The call for underground building increases especially in densely populated areas. Often these densely populated areas are near coastal regions where soft soil conditions are present in many cases and where structures are founded on timber piles. Underground building activities generally cause some subsidence on ground level, which in turn may lead to structural damages (cracks). As a result, disputes may arise between the building owners and the contractors of the underground building activities. An assessment of the foundation may be necessary to settle the disagreement.

Soil cleaning: Contaminated soil may be present under houses in the vicinity of old factories and on brownfield locations. When the contaminated soil has to be removed, the timber foundation needs to be assessed for strength and the possibility to withstand a temporary open air climate. Removal of soil has a second negative consequence. Due to the fact that vertical soil stresses reduce when soil is removed, the load carrying capacity of the foundation will consequently be reduced.

Strategic maintenance planning: Maintenance schemes for other types of works of infrastructure may benefit from a combination of activities. Planned maintenance or renewal of cable networks, sewage systems, road and pavement surfaces may benefit from combined works. Redirection of traffic, losses in turnover of companies near the works and social problems 
associated with the works are important parameters in maintenance planning which could include the (regular) assessment of structures.

\subsection{Assessment techniques}

Several possibilities exist for the assessment of timber structures [2,3]. It is outside the scope of this paper to deal with all of the available techniques, but they can be divided into the following main areas.

Traditional inspection methods combining visual assessment and (sharp) tools.

NDT such as ultrasound and stress waves, but also Pilodyn hammer type equipment: The use of the Pilodyn hammer to determine the density is well documented for measurements on standing trees, sawn timber and timber suffering from decay, [4]. Ronca and Gubana [5] developed another "Pilodyn type", a so-called blow count type apparatus. This apparatus counts the average number of blows for penetrating a steel needle a certain distance in timber. A severe change in the number of blows indicates decay. The influence of moisture content was also given, so this equipment might be used also for wet foundation timber. The Pilodyn does not show an effect of penetration angle on the density determined, while the blow count apparatus shows higher resistance when used in tangential direction than in radial direction. The predicted strength increases accordingly, while this does not happen with the Pilodyn hammer.

Drilling and strength testing of bore cores: This technique allows estimating the residual strength of piles or gluelines of glulam beams. The correlation between the strength of bore cores and the compression strength is high and allows for the determination of the residual strength of piles without damaging the pile to an extent that they have to be replaced. Schwab et al. [6] and Rug and Seemann [7] have extensively described and tested the method. The results of Schwab et al. will be used in the analysis of Dutch test results on old piles.

Drilling methods based on torque resistance may also be used but are favoured for dry conditions in buildings. In addition, these types of drills must be operated with care, since they are not always optimised for the wood species under investigation.

Full scale pile testing: This is not always feasible and can be costly, but when large renovation works are planned, the effort of testing a number of piles is small compared to the potential benefits. In addition, testing of the piles increases the knowledge on strength reduction as a function of age and has therefore also benefits for other projects. The last two are of particular interest since they are the only measurement techniques, which give a direct indication of the residual strength of the full-size timber. The determination of the residual strength is of key importance in the assessment procedure, when estimations have to be made about the future use of the foundation.

Flow charts have been developed by a number of researchers and institutes in order to be able to make a reliable assessment $[2,3]$. Generally, these flow charts require analysis of the original structure, its uses, localization of defects/degradation and classification. On the basis of an analysis of the (historical) situation, the results of the inspection and the planned future use of the structure, an estimate is made on the residual lifetime and the necessity of repair or replacement. The age of a structure can often be estimated from historic files, but the load history is sometimes more complex, although for foundations the governing load can often easily be determined. Since timber has a load and time dependent strength, the full short term resistance based on modern design principles may no longer be fully available, especially in the case of foundations, where the ratio between dead and live load is quite different from floors and roofs. In this respect, timber from floor and roof structures can be expected to have $100 \%$ strength capacity $[8,9]$. The current state of the structure has to be determined. This will be discussed in the following paragraphs. The expected future loads can be determined from the new building plans or from current design codes. Depending on the situation and legal requirements, deviations from loads specified in design codes could be accepted in certain cases. The information obtained from the expected loads and the state of the structure allows for calculations of the residual strength of 
the structure and in conjunction with that the expected "remaining" service life.

\section{Strength research on old timber from foundations}

\subsection{Concert hall Amsterdam}

\subsubsection{Pile tests and specimen preparation}

A number of spruce piles of the Concert hall in Amsterdam were made available for research purposes at Delft University. The age of the piles was slightly over 100 years [10]. They were rammed between 1880 and 1983 and were removed from the foundation in 1986, kept in a saturated environment and delivered to the laboratory. The goals of the test programme were twofold. First, the strength of the piles was to be determined. In total seven full cross sections obtained from three different piles were tested. The second goal was to determine a positive or negative effect from temporary drying of the timber, for instance during a period of restoration works. The question was whether piles could be left to dry for a period of several months or whether protective measures need to be taken. From the piles, discs were sawn which in turn were divided into square compression test specimens, for the determination of the cross sectional strength and the influence of moisture content on the strength after a period of drying.

The strength of the piles with full cross section and saturated condition was determined in a standard compression test set-up. The amount of water pressed out during the tests, was almost completely sucked into specimen again during and after the unloading. The average, minimum, and maximum values are presented in figure 5 .

\subsubsection{Material properties}

The cross sectional strength of the spruce pile was determined by sawing a disc into a squared pattern of $35 \times 35 \times 210 \mathrm{~mm}$ specimens. These were tested in compression in fully saturated condition. The test procedure was according to ISO 3787 for compression parallel to the grain. Failure (or maximum load) was reached within $300 \pm 120 \mathrm{~s}$ with a constant loading head movement. The values have been plotted as a function of the distance to the pith. This is shown in Fig. 1. The pattern of lower strength around the centre of the piece and higher strength towards the outside is similar to that found in new wood (Deresse, [11]).

\subsection{Sluice at Schijndel}

\subsubsection{Pile specimen}

A 167 years old pile had been taken from a sluice in Schijndel, in the South-east of the Netherlands during renovation works [12]. The sluice had been built in 1821 and during renovation works the upper part of a pile was sawn off and delivered to the laboratory. The length of the piece was about $750 \mathrm{~mm}$. Visual inspection of the pile showed that the uppermost layer of the pile and the pin for the connection with the head-beam suffered from decay. The upper part of the pile was above ground level, but below water level, for a number of years before the renovation works started and the oxygen content of the water was raised considerably due to the effect of ship propellers.

\subsubsection{Material properties of cross sections}

The pile was treated as follows: two discs were sawn from the top and the bottom, each disc

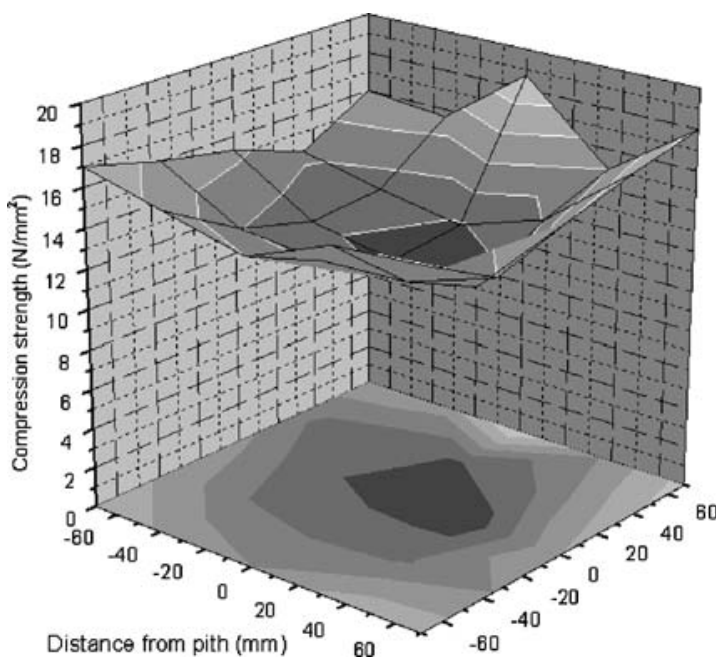

Fig. 1 Compression strength of a cross section of a 100 year old pile without decay 
having a thickness of about $100 \mathrm{~mm}$. From the two outer discs compression specimens were sawn with the following dimensions: $30 \times 30 \times 90 \mathrm{~mm}$, from the two inner discs compression specimens were sawn having dimensions of $20 \times 20 \times$ $60 \mathrm{~mm}$. From the squared pattern, the specimens were either tested in the fully saturated condition, or dried to approximately $13 \%$ moisture content. The compression strength of the pieces was determined in a standard testing machine. The remaining middle piece of the pile was tested as a full cross section. The compression strength was $10.5 \mathrm{~N} / \mathrm{mm}^{2}$. Location of the pith was determined and also the thickness of the sapwood. The latter can be difficult, since sapwood is not always recognizable with the naked eye.

In Fig. 2 the upper part is shown, while Fig. 3 shows the same pile at one meter depth. Clearly, on the upper part it can be seen that the outside is deteriorated to a very low strength level, but internal heartwood still has a resistance comparable to that of new spruce piles [13]. At $1 \mathrm{~m}$ depth, the strength is still equally distributed over the cross section.

\subsection{Drying of piles in open air}

As indicated earlier, piles sometimes have to be left in open air for a certain period of time, for instance when contaminated soil has to be removed or cleaned. The question was raised

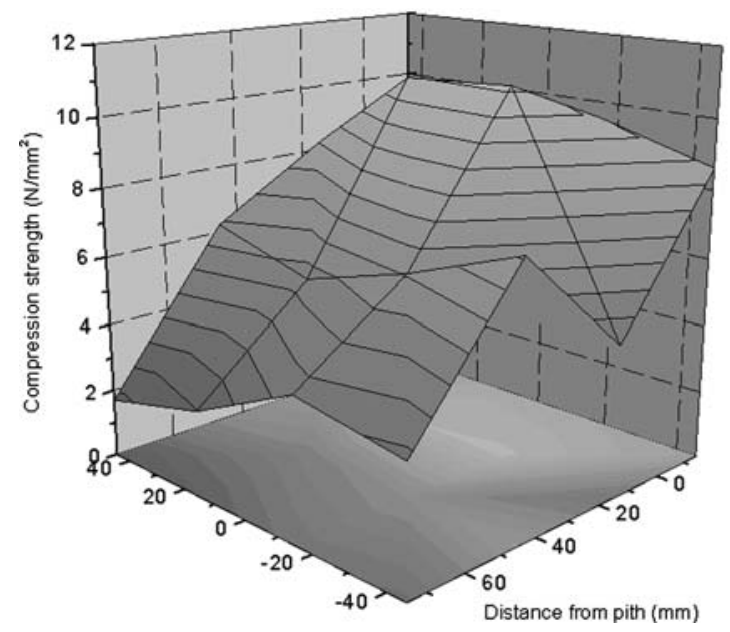

Fig. 2 Compression strength of a cross section of a 167 year old pile with decay

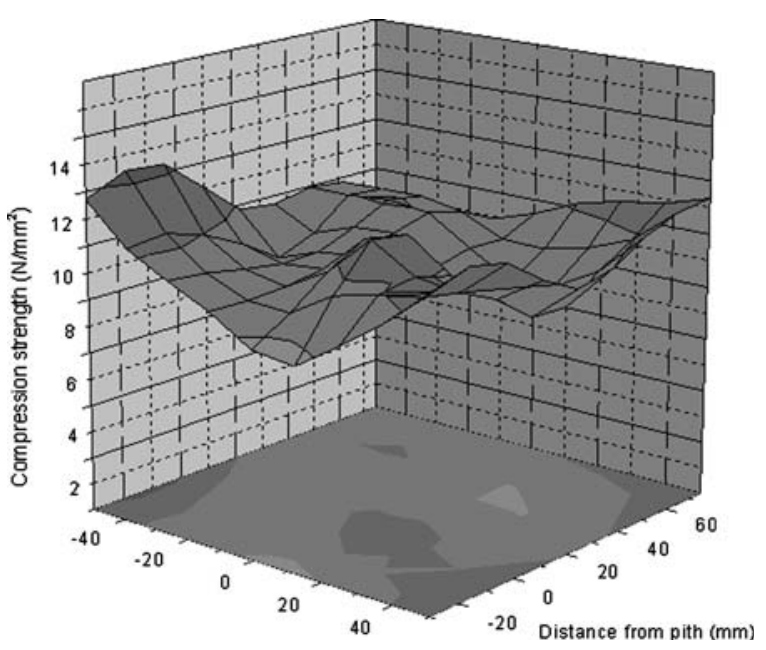

Fig. 3 Compression strength of the same pile at $1 \mathrm{~m}$ depth without decay

whether precautions need to be taken to prevent the piles from drying, as there were indications that timber stored under water for very long periods may sometimes disintegrate when dried. Therefore, additional discs were sawn from the piles from the Amsterdam concert hall to study the strength of dried specimens relative to wet specimens.

The discs were sawn again into square compression specimens with sizes $35 \times 35 \times 210 \mathrm{~mm}$. In addition to the series that were tested directly after removal of the piles, the following series were tested:

3 series in $20^{\circ} \mathrm{C}$ and $80-90 \% \mathrm{RH}$, to be tested after 3, 6 and 9 months;

3 series in a covered outdoor climate to be tested after 3, 6 and 9 months,

3 series of new spruce, dry and kept under water for 3 and 6 months.

In Fig. 4 the compression strength results of all the tests are shown as a function of the moisture content. Density of the spruce was about $420 \mathrm{~kg} /$ $\mathrm{m}^{3}$, related to a moisture content of $12 \%$. A failure in the measurement of the specimens that were kept in the $80-90 \%$ relative humidity resulted in a moisture content of around $12 \%$, where $18-20 \%$ was expected. Despite this moisture content error, the trend is clear: above $30 \%$ moisture content there are no hard conclusions to be drawn that timber from old piles is weaker 


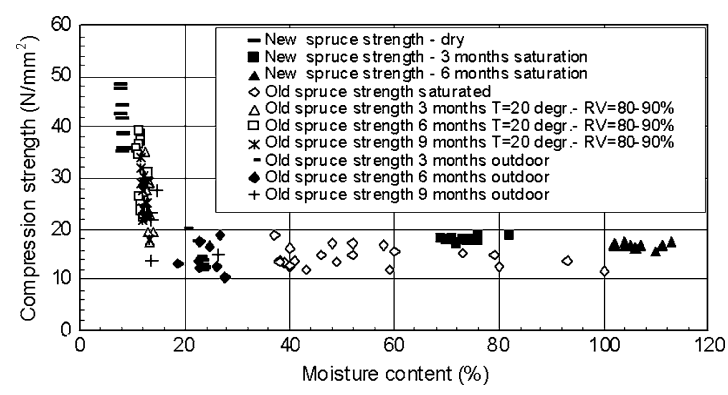

Fig. 4 Compression strength of temporary dried timber from foundation piles

than new timber, and drying of timber from old piles leads to a strength increase. Consequently, from these results it can be concluded that timber free from decay can be left in a (covered) open air climate for at least a period of 9 months, without additional measures to be taken. It is assumed that the possible occurrence of longitudinal cracks as a result of drying is not influencing the compression strength parallel to the grain in a negative way.

\subsection{Comparison with strength data from literature}

In Fig. 5 the results of parallel to the grain tests are shown, taken from small round specimen drilled from piles [4]. The age of the piles varied between 70 years and 640 years. The scatter is very large (Schwab et al. [6]), but still some conclusions can be drawn. The strength decreases with age, but the cause of the strength decrease is not known with certainty, but many factors play a role [15]. Both load and decay will cause a reduction in strength and since the load level during the service life was not known, mechanical damage will have accumulated to a certain extend. The straight lines have been determined on the average values of the test data of the heartwood and sapwood data respectively. The test results on full piles from Delft University have been added. These piles had an age of 100 years (six specimens) and one of 167 years. The strength ratio of these data has been calculated on the basis of the average strength value in wet condition of new spruce piles which has been determined at 20.0 Mpa [13]. The results fit in quite well and indicate that the residual strength of piles is mainly governed by the amount of heartwood in the cross section. It must be kept in mind that is not known to which load level the piles have been loaded. The construction of foundations was based more on experience than on engineering practise and therefore stress levels are difficult to be determined when structures of one hundred years of age or more are studied.

\section{Influence of decay on timber strength}

Timber in ground may suffer from decay by fungi or bacteria. Fungal decay may occur when the ground water level decreases below the upper
Fig. 5 Resistance of timber from foundations after service life

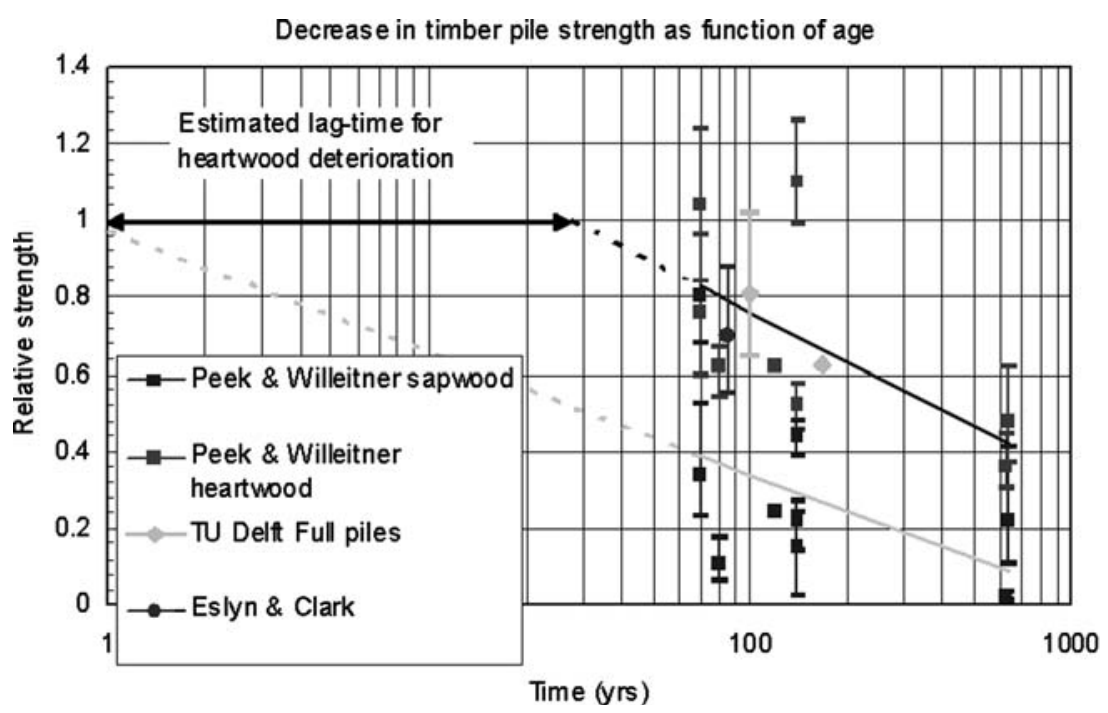


part of the pile. Bacterial decay is much slower but can also take place below the ground water level. Clearly, in Fig. 2, the upper part of the pile shown shows severe decay on the outside. This is generally the sapwood area, while the inner heartwood is much more durable. Liese and Stamer [16] studied the influence of brown rot on the compression strength. The fungi studied are the very common and comprised Merulius lacrimans, Coniophora cerebella, Serpula himantioide and Poria vaporaria. The relative strength of the timber decreased by $30-100 \%$ within a time span of just $300 \mathrm{~h}$.

The size of the specimens used was not given, so the penetration rate of the decay as a function of time could not be derived. This, from an engineering point of view, is equally important as the rate of decay, since this influences the remaining service life to a great extent. Wilcox [17] as well as Kothe [18] have shown the influence of certain types of decay on the residual strength by means of mass loss-strength relationships and by reduced cross sections, see Fig. 6 . This allows for assumption on the residual strength of structural elements when they have been attacked by fungi.

More recently, Thornton et al. studied the rate of decay in timber poles at ground level [19]. The rate of decay was found to be about $1.3 \mathrm{~mm} / \mathrm{year}$ for Douglas fir in moderate decay hazard circumstances.

Pile foundations where decay is present do not necessarily have lost their load carrying capacity to such extend that replacement becomes unavoidable. If the sapwood of timber piles is deteriorated, the remaining heartwood section

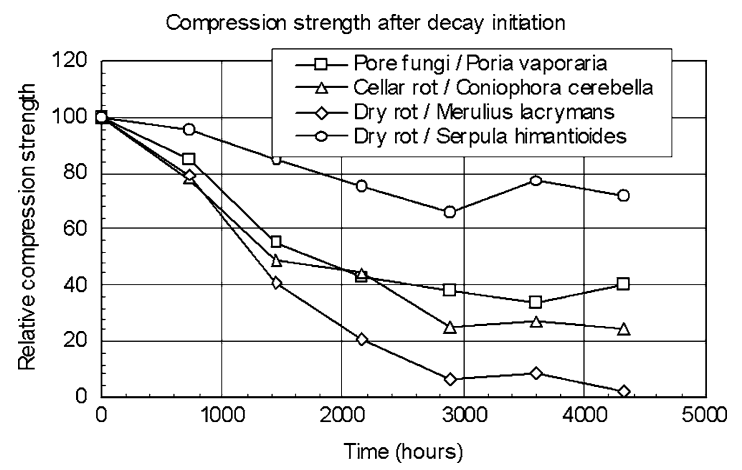

Fig. 6 Relative compression strength [18] might still have sufficient load carrying capacity. Consequently, the ratio between decayed area and non-decayed area is an important parameter that can be used when the remaining lifetime of the structure has to be determined. In addition, depending on the type of decay, the strength of decayed timber is not necessarily zero. The strength of decayed timber may still serve in safety calculations.

\section{Service life and damage modelling}

After an assessment of the foundation, the final step is to predict the load carrying capacity and the residual lifetime. The residual lifetime should be estimated in order to be able to determine the necessity of repair or replacement. A new approach for this is the assessment of the strength of the pile by means of damage accumulation models. Damage accumulated models have been used in timber research describing the strength development of timber under long term loads. Several models have been developed for instance by Gerhards [20] that will be used here. Other damage models are available, for instance those of Foschi and Yao [21] and Nielsen [22]. Its parameters are relatively difficult to determine and show a large scatter between different timber species (Foschi et al. [21]) and joints [23]. The Foschi and Yao model was shown to be a special case of the damage model of Van der Put [24] which is based on true physical parameters (Krausz and Eyring 1975). Also the model of Gerhards can be related to "true" material properties, since it leads to the same type of equations as given by the damage model of both Caulfield [25] and Van der Put. Since these models only describe the strength development in time they have to be modified to include the influence of deterioration on the material properties. For instance biological degradation decay of the cross section that may have considerable effect on the strength capacity of members. By combining durability models with strength models, it becomes possible to model the "residual lifetime" of structures. Different approaches are possible using probabilistic calculations [26], of kinetic based models [27], but here 
the exponential damage accumulation model of Gerhards is used with modified strength values.

The limit state function on which most design codes are currently based is generally written as:

$Z=R-S$

with: $Z=$ the limit state; $R=$ the resistance; $S=$ the solicitation or load.

In reality, both the resistance and the solicitation are varying in time and the limit state function can be written as:

$Z(t)=R(t)-S(t)$

The solicitation $S(t)$ concerns all load types possible, such as mechanical or physical (temperature, moisture). A structure is assumed not to have failed while $Z(t)>0$. In Fig. 7 this is shown schematically.

The probability of failure increases, since the resistance of members generally decreases with age. In case of timber, the resistance $R(t)$ depends on the load and the load history. Mositure content and temperature also have an influence, but may be assumed constant for piles in the ground. Consequently, Eq. 2 can be written as:

$Z(t)=R(s(\tau), t)-S(t)$

For the resistance function $R(s(\tau), t)$, the Gerhards damage function is used here, which is easy and straightforward to use [20], but now the material strength is modified depending on the amount of decay and residual strength of decayed timber. Thus, a time dependent resistance $f_{\mathrm{s}}(\mathrm{t})$ is introduced in the model:

$\frac{d \alpha}{d t}=\exp \left(-C_{1}+C_{2} \frac{\sigma(\tau)}{f_{\mathrm{s}}(t)}\right)$

The damage $\alpha$ takes a value: $0 \leq \alpha \leq 1$. By definition, failure occurs when $\alpha=1$. This means that while $1-\alpha>0$ the structure is still able to carry the load at that point in time and $Z(t)=1-\alpha$. Consequently, the damage function can be used to estimate residual lifetimes of structures when the stress function $\sigma(\tau)$ representing the load path from the time of erection of the structure until the end of the time span under consideration is known as well the strength $f_{\mathrm{s}}(\mathrm{t})$ representing the time dependent load carrying capacity of the material.

With regard to the stress function $\sigma(\tau)$ it may be necessary to include other loads than mechanical. A "moisture load" due to humidity variations may be included in cases where tension stresses perpendicular to the grain are expected. For instance this is the case for curved or pitched cambered glued laminated members, where cracks have been discovered in the area with high stresses perpendicular to the grain, relatively early after erection of the structure [28]. The parameters $C_{1}$ and $C_{2}$ are determined from standard time to failure tests.

For pile foundations the normal force has to be checked against the load carrying capacity. When the cross section is denoted $A_{\text {tot }}$, the value of the pile resistance $F_{\mathrm{u}}$ is determined $F_{\mathrm{u}}=f_{\mathrm{c}, 0} A_{\text {tot }}$.
Fig. 7 Schematic representation of the distribution of lifetimes of structures (Siemes, personal communication)

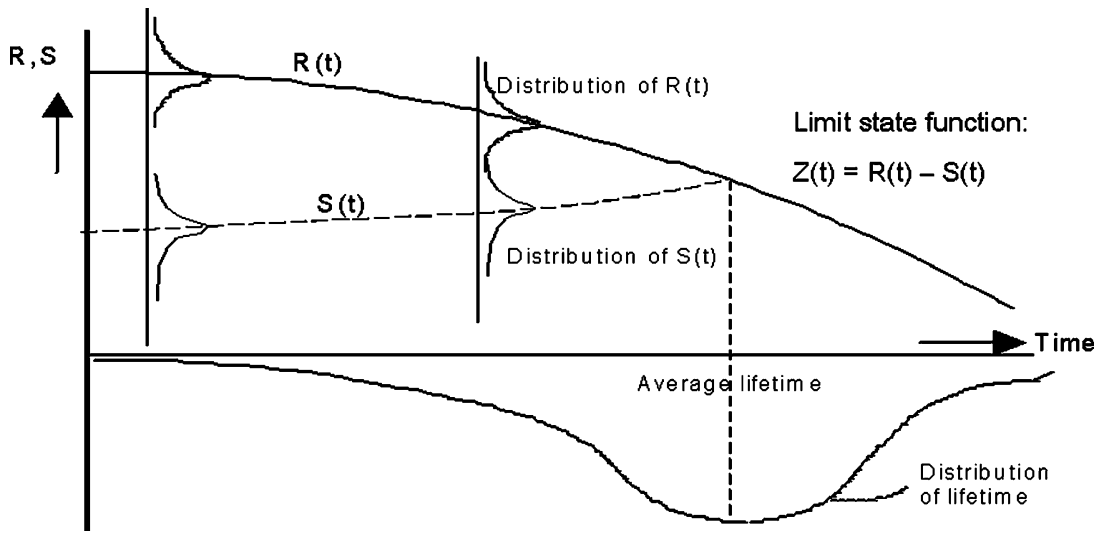


When it is assumed that the pile may suffer from decay, after a number of years the non-decayed cross section will be reduced to $A_{\text {rem }}$ (remaining cross section). Denoting $f_{\mathrm{c}}, 0$, dec the strength of the decayed timber and $A_{\mathrm{dec}}$ the cross section of the decayed area, the pile resistance can be written as:

$F_{\mathrm{u}}=f_{\mathrm{c}, 0} A_{\mathrm{rem}}+f_{\mathrm{c}, 0, \mathrm{dec}} A_{\mathrm{dec}}$

Equation 5 can be further modified into a more general form. When the ratio between the remaining non-decayed cross section and the total cross section is defined as:

$\delta=\frac{A_{\text {rem }}}{A_{\text {tot }}}$

and when the strength ratio between the decayed timber and the non-decayed timber is defined as:

$\beta=\frac{f_{\mathrm{c}, 0, \mathrm{dec}}}{f_{\mathrm{c} ; 0}}$

Eq. 5 becomes:

$F_{\mathrm{u}}=f_{\mathrm{c}, 0} A_{\mathrm{tot}}(\delta(1-\beta)+\beta)$

The value of $f_{\mathrm{s}}(t)$ in Eq 4 can be replaced by $F_{\mathrm{u}}$ when the stress function $\sigma(\tau)$ is replaced by the load. Both $\beta$ and $\delta$ can be made time dependent, for instance when the decay rate is known. The parameters $C_{1}$ and $C_{2}$ in the damage model are determined on the basis of time to failure tests on timber [20, 21] and joints [23].

An example will be shown on the basis of a problem regularly occurring with pile foundations. A typical pile foundation is shown in Fig. 8.

The assumed pile diameter where the load carrying capacity has to be verified is $160 \mathrm{~mm}$, with a characteristic load of $100 \mathrm{kN}$. As a result of unexpected decrease in ground water level the upper side of the pile was exposed to soil conditions leading to severe decay of the sapwood of the pile and after a number of years the cross section was decreased to $A_{\text {rem}}$. The lag time before decay is initiated in ground conditions above the ground water level is taken to be zero and it is assumed that the sapwood is deteriorated

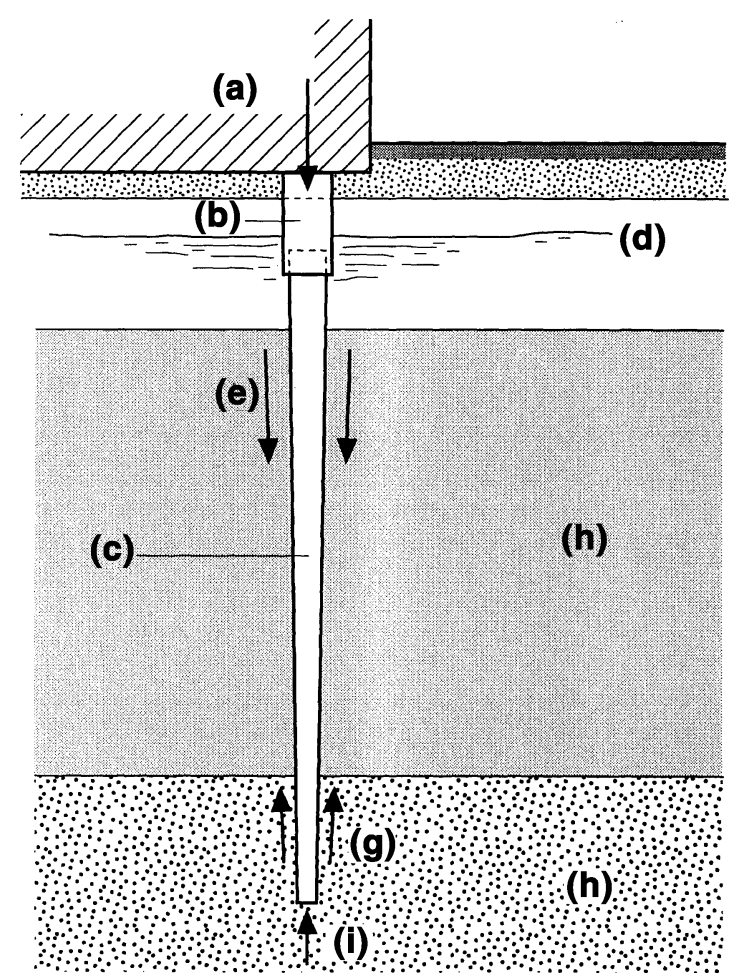

Fig. 8 (a) Structure, (b) concrete extension pile, (c) timber pile (tapered), (d) ground water level, (e) negative skin friction, (f) weak clay, (g) positive skin friction, (h) load bearing soil layer, (i) pile toe resistance

in a few years. In addition it is assumed that the ground water level records show that the level came below the top level of the piles 100 years after the foundation was built. Consequently, the cross section is reduced to $A_{\text {rem }}$ after 100 years in a way comparable to the reduction of the diameter as shown in Fig. 2, due to degradation of the outer layer.

In Figs. 9 and 10 the remaining service life predictions are calculated shown for three values of $\delta(\delta=0.8,0.7$ and 0.6$)$ and two value of $\beta$ $(\beta=0.5$ and 0.0$) . \quad \beta=0.0$ gives always a safe approximation since it neglects any contribution to the load carrying capacity of the decayed parts.

In this example the pile cross section is checked for safety against compression stresses parallel to the grain. Also, in this example decay was assumed to be initiated after 50 years of service life. In actual situations an estimate will have to be made about the load history of the structure and the decay, to be fed into the model. 
Lifetime prediction of timber piles - Decay initiated atter 100 years of service

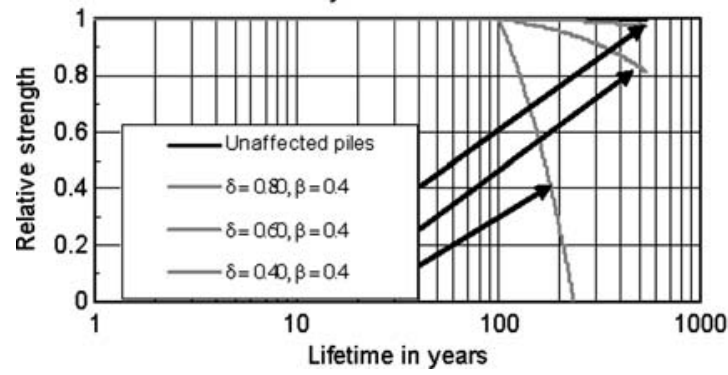

Fig. 9 Service life prediction for three levels of $\delta$ and $\beta=0.4$

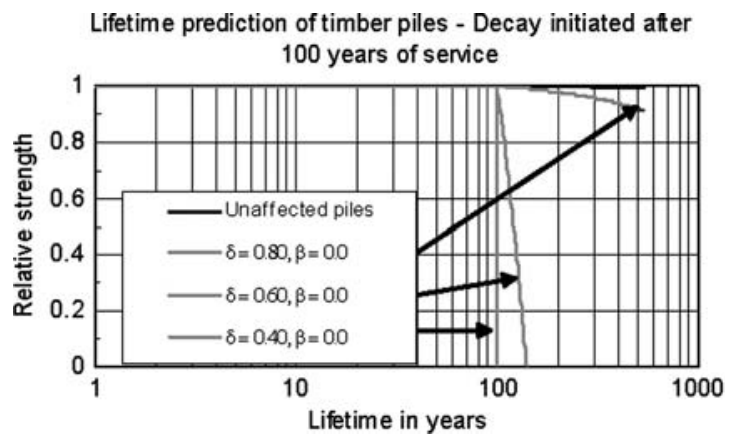

Fig. 10 Service life prediction for three levels of $\delta$ and $\beta=0$

Obviously, $\beta$ values close to zero results in a rapid drop in remaining service life. Besides the analysis of the influence of decay, the model can also be used to study the influence of safety factors. Both load and material factors can be analysed. Especially for existing structures that have to be assessed it may be necessary to have a closer look on those values.

\section{Other applications}

The approach given above may also be used for the assessment of other type structures than foundations. In monuments, very often large drying cracks have developed over time, especially when large beams have been used where the pith is located in the centre of the beam. Depending on the sizes of the cracks, repair measures may be needed in areas where shear stresses determine the design, i.e. near the supports. The mathematical form of Eqs. 5-8 remains the same. For shear the cross section of a beam $b \times h$ is needed in the calculations. When the cross section is decreased by drying cracks, width $b$ decreases from the original state to the cracked state $b_{\text {crack }}$ increasing the relative load level in Eq. 4. In most monuments, timber sizes are large and the drying cracks are located near the neutral axis, i.e. the location with the highest shear stresses. Consequently, $\delta$ as derived in Eq. 6 does not change and $\beta$ is always zero in case of a crack. The decrease in load carrying capacity as a result of drying cracks is generally small, since the actual shear resistance is often much higher than code values [29].

\section{Conclusions}

A damage model from literature with parameters derived from time to failure analysis of timber and timber joints have been combined with strength reduction models as a result of decay. An example in which a strength reduction factor was given for compression parallel to the grain was given and the influence on the residual lifetime could be shown. However, the same principle can be used to check bending stresses and support conditions. The combination of a damage model with deterioration influence on the strength properties has resulted in a model which can easily be used to study the sensitivity of structures for different load sets and material parameters. When structures are found with decay, either active or inactive, the model can also be used to analyse the effectiveness of different measures that can be taken and the influence of the future use of the structure. In this example the calculations have been made using fixed values, but probabilistic calculations could be made when both load and strength distributions are entered in the model.

Regarding the influence of decay on the strength it seems necessary that more knowledge is developed on the residual strength of decayed wood. May be even more important is the rate at which the decay reduces the cross section of timber elements. 


\section{References}

1. Eurocode 1 (1994) Basis of design and actions on structures. Part 1: Basis of design, ENV 1991-1, sept.

2. Bonamini G (1995) Restoring timber structures Inspection and evaluation, STEP Lecture D3, Centrum Hout, The Netherlands, ISBN 90-5645-002-6

3. Görlacher R (1999) Historische Holztragwerke. Untersuchen, Berechnen und Instandsetzen. Universität Karlsruhe (TH), Karlsruhe

4. Görlacher R (1987) Zerstörungsfreie Prüfung van Holz: Ein in "situ"-Verfahren zur Bestimmung der Rohdichte. Holz als Roh- und Werkstoff 45, pp 273-278

5. Ronca P, Gubana A (1996) Evaluation of actual ultimate strength in wooden structures by means of in situ penetration test. International Wood Engineering Conference, Vol III, pp 226-232, New Orleans, 1996

6. Schwab E, Waschau A, Willeitner H (1982) Bohrkerne zur Beurteilung der Festigkeit hölzerner Rammpfähle, Bauen mit Holz 9, 84, 1982

7. Rug W, Seemann A (1988) Festigkeit von Altholz. Holztechnologie 29(4):186-190

8. Kuipers J (1986a) Effect of age and/or load on timber strength. CIB-W18 Timber Structures, paper 19-6-1, Florence, Italy

9. Kuipers J (1986b) Effect of age and/or load on timber strength. CIB/W18 Timber Structures, Paper 19-6-1, Meeting 19, September 1986, Florence, Italy

10. Van Bueren R (1987) Druksterkte van 100 jaar oude houten funderingspalen van het Amsterdamse concertgebouw. TU Delft report 25-87-41/16-HE-13, October 1987

11. Deresse T (1988) The influence of age and growth rate on selected properties of Main-grown red pine. University of Maine, Orono, ME. Ph.D. Thesis

12. Kurstjens PBJ (1988) De druksterkte van een 167 jaar oude heipaal uit de sluis nr. 3 te Schijndel TU Delft report 25-88-36/05-HE-18, June 1988

13. Van de Kuilen JWG (1994) Bepaling van de karakteristieke druksterkte van houten heipalen. TNO-report 94-CON-R0271, 1994 (in Dutch)

14. Peek R-D, Willeitner H (1981) Behaviour of wooden pilings in long time service, Proc. Tenth Conference International Society of Soil Mechanics and Foundations, Vol III, 9/23, pp 147-152, Stockholm, Sweden

15. Varossieau WW (1949) Opgegraven en aangetast hout uit biologisch oogpunt bezien. CIMO Delft, 1949
16. Liese J, Stamer J, Angewandte Botanik Bd. 16, 1934 Page 363. [Referenced from Kollman]

17. Wilcox WW (1978) Review of literature on the effects of early stages of decay on wood strength. Wood Fibre 9(4):252-257

18. Kothe E (1988) Auswirking van Holzschäden durch Pilze und Insekten auf die Standsicherheit van Holzbauwerken - eine Bestandsaufnahme. Bautechniek 75, Heft 8 pp 552-558

19. Thornton J, Johnson G, Nguyen J-K (1994) Specimen life statistics and mean rates of biodeterioration for untreated heartwood timbers exposed in-ground for 23 years. PTEC proc., pp 449-453

20. Gerhards CC, Link CL (1987) A cumulative damage model to predict load duration characteristics of lumber. Wood Fibre Sci 19(2):147-164

21. Foschi RO, Yao RC (1986) Another look at three duration of load models. CIB/W18 Timber Structures, Paper 19-9-1, Meeting 19, September 1986, Florence, Italy

22. Nielsen LF (1992) DVM Analysis of wood, lifetime, residual strength and quality. CIB/W18 Timber Structures, paper 25-9-2, Ahus, Sweden

23. Van de Kuilen JWG (1999) The residual load carrying capacity of timber joints, HERON Vol 44-3, pp 187214, ISSN 0046-7316, 1999

24. Van der Put (1986) TACM, A model of deformation and damage processes based on the reaction kinetics of bond exchange. IUFRO S5.02/CIB-W18/19-9-3, Meeting 19 Florence, Italy, 1986

25. Caulfied DF (1985) A chemical kinetics approach to the duration-of-load problem in wood. Wood and Fiber Sci 17(4):504-521

26. Leicester RH, Foliente GC, Cole IS, Wang C-H, Mackenzie C (2002) Prediction models for engineered durability of timber in Australia, 9th Int. Conf. on Durability of Building Materials and Components, March 2002, Brisbane, Australia

27. Winandy JF, Lebow PK, Murphy JF (2002) Predicting current serviceability and residual service life of plywood roof sheathing using kinetics-based models. 9th Int. Conf. on Durability of Building Materials and Components, March 2002, Brisbane, Australia

28. Morlier P, Ranta-Maunus A (1998) DOL effects of different sized timber beams. Holz als Roh- und Werkstoff 56

29. Frech P (1987) 'Beurteilungskriterien fur Rissbildungen bei Bauholz im konstruktiven Holzbau'. Bauen mit Holz, 9 